\title{
TOPOLOGIA DO CIBERESPAÇO: redes sociais, aprendizagem colaborativa e matemática para além da sala de aula
}

\author{
CYBERSPACE TOPOLOGY: social networks, collaborative learning, \\ and math beyond the classroom
}

\author{
Ana Carolina Carius ${ }^{1}$
}

\section{RESUMO}

O presente trabalho apresenta o estudo da relação social e colaborativa no ciberespaço entre os estudantes de uma turma de ensino médio. O público participante é um grupo de estudantes matriculados em um curso técnico em química integrado de uma escola técnica da região metropolitana do estado do Rio de Janeiro. Por meio da proposição de uma atividade em grupo que integrou matemática e química, o objetivo foi analisar o comportamento dos estudantes no ciberespaço, do ponto de vista colaborativo, bem como a importância dessa interação para a realização da atividade. Como metodologia de pesquisa, utilizou-se a pesquisa-ação para a análise offline dos atores envolvidos e a observação participante para a análise online dos mesmos atores, atuantes em uma rede social. A Análise de Redes Sociais (ARS) foi o instrumento usado para o mapeamento do ciberespaço e caracterização das interações entre os estudantes. Com base nos resultados da ARS, em conjunto com a análise dos trabalhos apresentados pelos grupos envolvidos na atividade, concluiu-se que os grupos com maior interação na rede social obtiveram maior competência na apresentação do produto final, assim como compreenderam com maior nitidez os objetivos dessa atividade, desenvolvendo diversas habilidades extracurriculares. Portanto, o ciberespaço, particularmente representado pelas redes sociais, conduz a uma nova forma de construção e disseminação do conhecimento, também modificando as relações sociais ambiente educacional.

Palavras-chave: Ciberespaço; Aprendizagem Colaborativa; Análise de Redes Sociais (ARS); Matemática.

1. Professora do Ensino Básico, Técnico e Tecnológico do Instituto Federal de Educação, Ciência e Tecnologia do Rio de Janeiro (IFRJ) e professora adjunta da Universidade Católica de Petrópolis (UCP). E-mail: ana.carius@ifrj.edu.br 


\section{ABSTRACT}

This paper presents the study of the social and collaborative relationship in cyberspace among students in a high school class. The group of students enrolled in an integrated chemistry technical course at a technical school in the metropolitan region of Rio de Janeiro was chosen as a participating public. Based on the proposition of a group activity to which mathematics and chemistry were integrated, the objective was to analyze the behavior of students in cyberspace, from a collaborative point of view, as well as the importance of this interaction for the accomplishment of the activity. As research methodology, action research was used for offline analysis of the actors involved and participant observation for online analysis of the same actors, acting in a social network. Social Network Analysis (SNA) was the instrument used to map cyberspace and characterize interactions among students. Based on the results of the SNA, together with the analysis of the work presented by the groups involved in the activity, it was concluded that the groups with the greatest interaction in the social network obtained greater competence in presenting the final product of the activity, as well as understood more clearly. its objectives, developing various extracurricular skills. Therefore, cyberspace, particularly represented by social networks, leads to a new form of knowledge construction and dissemination, modifying social relations also in the educational environment.

Keywords: Cyberspace; Collaborative Learning; Social Network Analysis (SNA); Mathematics.

\section{Introdução}

É inegável que a sociedade vem passando por transformações importantes relacionadas a inserção da internet no cotidiano das pessoas. O uso de softwares e aplicativos para a realização de tarefas as quais apenas o homem exercia anteriormente, reflete mudanças significativas nas relações sociais, bem como na relação entre o homem e os objetos. Pierre Lévy (1999, p.41), o "ciberespaço compreende materiais, informações, seres humanos e os programas." Portanto, no contexto deste trabalho, define-se como ciberespaço esse "local" no qual se articulam computadores em suas diversas formas, programas (softwares ou aplicativos), informações e seres humanos os quais relacionam esses atores, em analogia ao conceito de Lévy.

A relação da humanidade com o saber não está imune às mudanças que vem ocorrendo. De acordo com Lévy (1999), nunca antes na história da humanidade a maioria das competências adquiridas por uma pessoa no início de sua carreira estariam obsoletas ao final de seu percurso pro- 
fissional. O autor destaca que o ciberespaço suporta tecnologias intelectuais capazes de amplificar, exteriorizar e modificar numerosas funções cognitivas humanas, como a memória, a imaginação, a percepção e o raciocínio. Portanto, a forma como os estudantes, em contato desde pequenos com o ciberespaço, compreendem e lidam com o acesso à informação e constroem seu conhecimento é bem distinta de estudantes de décadas anteriores, os quais não foram submetidos aos mesmos estímulos.

Na mesma direção de Lévy, Boaler (2018) argumenta que a matemática escolar está cada vez mais desconectada da matemática usada pelos matemáticos e da matemática da vida. Para a autora, o desperdício de tempo e energia com procedimentos e cálculos que jamais serão utilizados na vida do estudante ou em seu trabalho, corrobora para o anacronismo entre o ensino tradicional e a real necessidade de desenvolvimento do raciocínio matemático nos estudantes, desde o início de sua vida escolar. Boaler (2018) conclui que os empregadores atuais não precisam mais empregar pessoas para realizar cálculos, pois estes são realizados por computadores. Precisam de pessoas que saibam raciocinar. O trabalho em equipe, tão valorizado pelos empregadores atuais, baseiase no raciocínio matemático.

Wagner (2008) descreve sete "habilidades de sobrevivência" para o novo mundo do trabalho: pensamento crítico e solução de problemas; colaboração em rede e aprendizagem por influência; agilidade e adaptabilidade; iniciativa e empreendedorismo; comunicação oral e escrita eficaz; acesso a informações para análise e, por fim, curiosidade e imaginação. $\mathrm{O}$ autor discute como essas sete novas habilidades, tão necessárias para os cidadãos do século XXI, não são desenvolvidas pelas escolas e, portanto, estas não conseguem preparar os estudantes para o mundo atual, sobretudo no que se refere aos avanços tecnológicos.

No entanto, a inserção dos smartphones no cotidiano dos estudantes e, consequentemente, a entrada destes aparelhos nas salas de aula, modifica o espaço físico de "aquisição de conhecimentos". Se antes as leituras, exercícios e discussões estavam restritas ao ambiente físico da sala de aula, agora estes podem se prolongar através de sites de busca, emails, aplicativos de mensagem e sites de redes sociais, por exemplo. Entende-se por redes sociais sites ou aplicativos os quais permitem emissão de mensagens (públicas ou privadas) os quais permitem interação com outros atores através de emissão de mensagens (postagens, 
troca por chats, hashtags). Os professores, antes os "detentores do saber", são convidados a atuar como mediadores do processo de construção do conhecimento, habilidades e competências, onde acumular informações torna-se irrelevante quando se as obtém com facilidade pela internet, através dos smartphones. Para Lévy (1999), a internet fomenta um novo estilo de pedagogia, a qual favorece ao mesmo tempo as aprendizagens personalizadas e a aprendizagem coletiva em rede, sendo o professor um animador da inteligência coletiva de seus grupos de alunos em vez de um fornecedor direto de conhecimentos.

O presente trabalho tem por objetivo analisar as relações sociais e colaborativas no ciberespaço, por parte dos estudantes, e como tal fato reflete o tipo de trabalho iterativo desenvolvido pelos atores em estudo. Avalia-se, também, os desdobramentos desta atividade na construção do conhecimento, individual e coletivo. Acredita-se, então, que seja possível responder à seguinte questão de pesquisa: a colaboração no ciberespaço, evidenciada pelas redes sociais, contribui para o desenvolvimento de habilidades e competências nos estudantes, além de oportunizar situações nas quais o estudante constrói o seu próprio conhecimento?

Desta forma, a pesquisa se justifica diante da necessidade de modernização do ambiente escolar, tomando-se como referência as novas habilidades as quais a escola deve desenvolver nos estudantes, considerando-se, também, a facilidade de acesso e utilização de smartphones por estes. A proposta se resume em apresentar um problema químico, descrito como o cálculo do $\mathrm{pH}$ de algumas substâncias a partir da solução proveniente do repolho roxo. Baseados na coloração gerada pelas misturas entre a solução do repolho roxo e outras substâncias, como o limão, álcool e vinagre, os estudantes foram convidados a calcular a concentração de íons $\mathrm{H}^{+}$a partir da definição matemática do $\mathrm{pH}$, utilizando o logaritmo de base 10. Por fim, estes classificaram as soluções entre mais ácidas e mais básicas utilizando os valores obtidos para o $\mathrm{pH}$. O procedimento, cálculos e conclusões deste trabalho foram entregues em formato de um vídeo, confeccionado e editado também pelos estudantes.

A fim de avaliar a colaboração dos estudantes na execução do trabalho, estes utilizaram o aplicativo de mensagens Whatsapp. Em virtude da afinidade dos estudantes com o aplicativo de mensagens e sua utilização frequente no cotidiano (incluindo a formação, anterior ao trabalho em discussão nesse texto, de um grupo de discussão da própria turma). Cada equipe de alunos construiu um grupo de discussão no aplicativo, 
no qual o professor regente da disciplina também participava. O objetivo da construção deste grupo foi aferir, a partir da rede constituída pelos diálogos entre os componentes deste, o nível de cooperação entre os membros e a interação entre eles. A entrega do vídeo deveria também ser feita através do aplicativo por meio do grupo de discussão formado.

A análise dos diálogos foi realizada através do método Análise de Redes Sociais (ARS), oriundo da área de comunicação. Tal método se constitui pela construção dos grafos que representam as redes. No caso deste trabalho, foram construídos os grafos correspondentes a cada grupo de discussão do trabalho no aplicativo Whatsapp. Cada estudante e o professor foram representados pelos vértices dos grafos e cada diálogo entre dois ou mais componentes do grupo foi representado por arestas. A discussão dos grafos utilizou o aplicativo NodeXL.

O presente texto apresenta as seguintes discussões: uma breve definição e conceituação relacionadas à ARS. Em seguida discute-se as mudanças dos ambientes de aprendizagem influenciadas pela introdução da internet e modificações oriundas desta introdução para as práticas pedagógicas. A seguir, apresenta-se a metodologia da pesquisa, destacandose a coleta de dados online e offline e a análise dos resultados. Encerrase o trabalho com as conclusões a respeito do estudo.

\section{Redes sociais: Análise de Redes Sociais (ARS) e a Teoria Ator-Rede (TAR)}

$\mathrm{O}$ acesso a internet não ocorre sem o intermédio de um objeto que conecte o ser humano ao ciberespaço. Inicialmente acessada pelos computadores estáticos, à medida que dispositivos móveis de acesso se proliferaram na sociedade, pode-se dizer que o ciberespaço está aberto a todos, desde que possuam um dispositivo (móvel ou não) com acesso à internet.

Bruno Latour (2012) advoga uma nova forma de se entender as relações sociais, não mais estabelecidas apenas pelos atores humanos. Ao considerar que os objetos também atuam, influenciando as relações sociais, Latour (2012) apresenta uma nova perspectiva sociológica, denominada de sociologia da tradução, em contrapartida à sociologia do social, tradicionalmente estabelecida. A chamada Teoria Ator-Rede 
(TAR) oferece um contraponto aos estudos em ciência e tecnologia, baseada essencialmente no fato de que o social não é uma substância, mas algo que se constrói no próprio desenvolvimento das ciências e das técnicas (BASTOS et al., 2014).

Para Latour (2012), qualquer coisa que modifique uma situação fazendo diferença é um ator - ou caso ainda não tenha figuração, um actante. Restringindo a análise ao ciberespaço, pode-se inferir que, sem um objeto (smartphone, tablet, notebook, computador) conectado à internet, não é possível acesso ao ciberespaço e, portanto, estabelecer relações sociais neste ambiente. Portanto, o dispositivo que acessa a internet é um actante na perspectiva latouriana.

Uma vez estabelecido o acesso ao ciberespaço, cada ser humano, munido de um dispositivo de acesso à internet, atua nessa grande rede de relações sociais. Pode-se estabelecer redes a partir de páginas da web, de sites de redes sociais, aplicativos de mensagens, blogs, aplicativos de serviços, entre outros.

Uma ferramenta matemática utilizada para o estudo do ciberespaço é a teoria matemática dos grafos. Foi com Euler, a partir do problema das pontes de Königsberg, que a primeira estrutura composta por vértices e arestas ganhou forma e passou a ter suas propriedades matemáticas estudadas (BARABÁSI, 2003). A teoria dos grafos, iniciada com Euler e posteriormente estudada por vários matemáticos renomados como Erdós e Rényi, expressa, do ponto de vista topológico, o ciberespaço. Tal fato possibilitou o estudo das relações sociais neste ambiente, sobretudo pelo fato de se conseguir armazenar, com o advento tecnológico, uma quantidade de dados nunca antes armazenada, com os quais foi possível rastrear as relações sociais.

A partir de estudos sobre o ponto de vista topológico do ciberespaço, estudos de redes sociais na internet passaram a ser realizados tanto pelos cientistas sociais quanto pelos matemáticos e profissionais da ciência da computação. Segundo Recuero (2018), a abordagem de rede (estudo de redes sociais a partir de ferramentas matemáticas sustentadas pela teoria de grafos) fornece ferramentas únicas para o estudo dos aspectos sociais do ciberespaço: permite estudar a criação de estruturas sociais; suas dinâmicas; as funções das estruturas e as diferenças entre os variados grupos e seu impacto nos indivíduos. 
Considerando-se a abordagem de Recuero (2018), o estudo das redes sociais compreende o estudo de padrões de conexões expressos no ciberespaço. Explora-se uma metáfora estrutural para compreender elementos dinâmicos e de composição dos grupos sociais.

Desta forma, a Análise de Redes Sociais (ARS), caracterizada pelo estudo das conexões existentes no ciberespaço se distancia da Teoria Ator-Rede (TAR), de Latour (2012). Uma vez que Latour (2012) define os actantes como unidades objetivas, mas como "relações", ou seja, de forma semiótica, estes tornam-se unidades potenciais de análise, enquanto os nós dos grafos estudados na ARS se referem a unidades objetivas de análise (BASTOS et al, 2014).

Em função dos objetivos deste trabalho estarem alinhados com a proposta de observação dos padrões de conexão do grupo participante do estudo, optou-se pela análise do ciberespaço a partir da ARS.

\section{Principais elementos da ARS: parâmetros para a topologia do ciberespaço}

A Análise de Redes Sociais (ARS) se baseia na análise de grafos que são construídos a partir da rede em discussão. Um ator, para a ARS, refere-se ao indivíduo ou coletivo de indivíduos considerados como nós da rede, representado pelo vértice do grafo. As conexões estabelecidas entre os atores nas redes sociais, representadas pelas arestas entre os nós, referem-se aos elementos de conexão que são decididos e apontados pelo pesquisador (RECUERO et al., 2018).

Desta forma, diversos conceitos relacionados aos nós e a rede foram introduzidos para que a topologia de cada rede em análise fosse caracterizada e, por conseguinte, parâmetros de comparação entre diferentes redes conduzissem, de fato, ao mapeamento das relações sociais no ciberespaço.

Recuero et al. (2018) dividem as métricas associadas à ARS em dois grupos: métricas associadas aos nós e métricas associadas à rede. Em relação aos nós, define-se como grau do nó o conceito de grau do vértice proveniente da teoria dos grafos, ou seja, representa o número de conexões que um determinado nó possui. O grau de intermediação, também chamado de Betweenness é uma medida de centralidade associada ao nó que mede o nível "entre" diferentes grupos que o nó está, ou seja, avalia 
o número de vezes que o nó é ponte entre grupos distintos. O grau de proximidade, também chamado de Closeness, é a métrica que avalia o quão próximo um determinado nó está dos demais na rede. A centralidade de autovetor considera não apenas as conexões dos nós que são avaliados, mas também suas conexões indiretas, ou seja, aquelas conexões dos que estão conectados ao nó em questão. Por fim, o PageRank qualifica as conexões recebidas e realizadas, estimando a importância de um determinado nó na rede se outros nós igualmente relevantes fazem conexões a ele. É uma variação da centralidade de autovetor.

Ainda de acordo com Recuero et al. (2018), define-se como métricas associadas a rede àquelas que dizem respeito a medidas em que o nó não é o foco central, mas este está, principalmente, na dimensão da rede como um todo e em suas propriedades e características. A densidade do grafo refere-se à quantidade de conexões existentes em relação ao número total de conexões possíveis. Portanto, quanto maior a densidade, maior a interconexão do grafo. O coeficiente de clusterização é um conceito associado à grupabilidade, sendo uma medida que expressa o grau de ligação entre os nós, a qual pode ser dividida em local e global. A medida de grupabilidade global expressa o nível de agrupamento na rede completa, enquanto a medida de grupabilidade local indica o grau de inserção de um nó específico dentro dos grupos existentes na rede. Para Barabási (2003), o coeficiente de clusterização indica o grau de coesão de nosso círculo de amigos. Um número próximo de 1 indica que todos os nossos amigos são bons uns com os outros, isto é, não há necessidade de cada um de nós reunir nossos amigos pois eles se relacionam bem entre si independente da nossa presença. Por outro lado, se o coeficiente de clusterização for próximo de zero, significará que somos os únicos que agregamos os nossos amigos, pois estes parecem não apreciarem as companhias uns dos outros. Ou seja, nossos amigos só se relacionam em encontros com a nossa presença e, sem esta, não se falam.

A partir das definições descritas nessa seção, faz-se importante refletir como as redes sociais, formadas no ciberespaço, influenciam as formas de colaboração, trocas de conhecimento e ampliam as discussões sobre assuntos que, antes do advento da internet, estavam restritos ao espaço físico da sala de aula. Tais desdobramentos permitem uma reconfiguração dos ambientes de aprendizagem, das competências e habilidades realmente necessárias aos cidadãos atuais, assim como de uma atualização das práticas pedagógicas por parte dos docentes. 
Para este trabalho foi escolhida a ARS como estratégia de análise para o ciberespaço em função do caráter pragmático que esta exerce sobre os sujeitos envolvidos no ciberespaço e as relações desenvolvidas por estes, contrapondo-se aos conceitos da TAR. Como referência para a ARS neste trabalho se utilizou os conceitos descritos e especificados por Recuero et al. (2018).

\section{Novas formas de aquisição de conhecimento conduzem a no- vas práticas pedagógicas}

O acesso indefinido a toda e qualquer tipo de informação modifica, substancialmente, as formas de conhecimento, bem como o papel da escola neste universo. Gómez (2011) observa que a sociedade atual, tida por sociedade da informação e do conhecimento, endereça à educação demandas diferentes das tradicionais, claramente relacionadas com o desenvolvimento, em todos os cidadãos, da capacidade de aprender ao longo da vida, corroborando com Lévy (1999) a respeito da obsolescência da formação inicial dos cidadãos atuais.

Um dos termos-chave mais utilizados em documentos recentes que norteiam a educação, como os documentos da OCDE (Organização para a Cooperação e Desenvolvimento Econômico), é competência. Goméz (2011) argumenta que os significados discrepantes para este termo podem conduzir a uma definição equivocada para este e, consequentemente, modificações substanciais no ambiente escolar são negligenciadas em função da pouca objetividade sobre o termo.

Diante das diversas utilizações e usos para o termo competência, Zabala e Arnau (2010) propõe uma definição para este a qual será adotada para este trabalho. Portanto competência é a capacidade ou habilidade para realizar tarefas ou atuar frente a situações diversas, de forma eficaz, em um determinado contexto no qual é necessário mobilizar atitudes, habilidades e conhecimentos ao mesmo tempo e de forma interrelacionada.

Segundo a Base Nacional Comum Curricular (BRASIL, 2018, p.8),

"competência é definida como a mobilização de conhecimentos (conceitos e procedimentos), habilidades (práticas, cognitivas e socioemocionais), atitudes e valores para resolver demandas complexas da vida cotidiana, do pleno exercício da cidadania e do mundo do trabalho." 
Para este trabalho, em função da utilização de conceitos associados à Base Nacional Comum Curricular, a definição de competência adotada é a vinculada neste documento.

Uma vez que as novas formas de conhecimento estão associadas ao desenvolvimento de novas competências, como argumenta Wagner (2008), sincrônicas às necessidades da sociedade atual, Gómez (2011) observa que não está claro, para a maioria dos docentes, que as novas exigências e condições da sociedade baseada na informação removem, de modo drástico, os fundamentos da escola clássica e de seus modos de entender o conhecimento. Consequentemente, novas práticas pedagógicas emergem para a compreensão deste novo modelo.

Tardif (2014) discute a importância do trabalho docente, envolvendo as diversas particularidades deste. Para o autor, "a pedagogia é a 'tecnologia' utilizada pelos professores em relação ao seu objeto de trabalho (os alunos), no processo de trabalho cotidiano, para obter um resultado (a socialização e a instrução)" (TARDIF, 2014, p. 117). Portanto, a tecnologia de que o professor dispõe é imprescindível nesse processo de modificação da escola clássica para a escola da sociedade da informação.

Para Gómez (2011), a função docente sofrerá uma mudança tão radical quanto o restante dos componentes do sistema educacional. Serão exigidas, para este docente, competências profissionais muito mais complexas que aquelas tradicionalmente exigidas, de forma que este possa enfrentar uma atividade tão rica quanto difícil: provocar, acompanhar, orientar e questionar a aprendizagem dos estudantes.

O estabelecimento da aprendizagem ativa objetivando-se o desenvolvimento de competências e habilidades por parte dos estudantes, convida os docentes a ofertar, em sala de aula, oportunidades de experimentação em situações cotidianas. Diante da mudança de paradigma da aquisição de conhecimento para a construção de conhecimento, por parte dos estudantes, a aprendizagem ativa e colaborativa se faz necessária.

Uma vez que a proposta da atividade em discussão neste trabalho é em grupo, González e Váttimo (2012) discutem que é possível encontrar três diferentes níveis no trabalho interativo: a equipe sem interação; a equipe onde há interação, mas sem mentalidade colaborativa e, por fim, a equipe onde há interação e mentalidade colaborativa. 
A seguir apresenta-se a metodologia da pesquisa para este trabalho, destacando-se a coleta de dados online e offline. A análise dos resultados da coleta online foi embasada nas métricas definidas anteriormente. Para a coleta offline, a observação e diálogos com os grupos, em sala de aula, permitiu complementar a análise online dos resultados.

\section{Metodologia da pesquisa: a coleta de dados online e offline}

A coleta de dados para este trabalho foi realizada a partir de uma atividade envolvendo química e matemática, para a primeira série do ensino médio, de um curso técnico em química integrado de uma escola técnica da região metropolitana do estado do Rio de Janeiro. Do ponto de vista da Base Nacional Comum Curricular (BNCC), o estudo dos logaritmos e funções logarítmicas está associado a exemplos práticos, como o cálculo do $\mathrm{pH}$. Uma das habilidades previstas para Matemática e suas Tecnologias na BNCC para o ensino médio é "Resolver e elaborar problemas com funções logarítmicas nos quais é necessário compreender e interpretar a variação das grandezas envolvidas, em contextos como os de abalos sísmicos, $\mathrm{pH}$, radioatividade, Matemática Financeira, entre outros". (BRASIL, 2018, p. 528)

A atividade proposta previa um procedimento prático para a aferição de $\mathrm{pH}$ a partir do repolho roxo. A escolha pela atividade com este tema deve-se ao fato deste estar previsto aos estudantes que estavam matriculados na disciplina de matemática e que participaram da atividade. Os estudantes já haviam estudado $\mathrm{pH}$ antes, tanto nas aulas de matemática quanto nas aulas de química. A atividade foi a última etapa do semestre letivo e os professores de matemática e química a discutiram, em conjunto, com os estudantes. Estes foram divididos em grupos de quatro ou cinco alunos e orientados a obter uma solução através do repolho roxo e, com esta, realizarem misturas com outras substâncias como álcool, vinagre e limão e observar a coloração obtida após o procedimento. Com fitas reagentes, por coloração, dependendo do $\mathrm{pH}$ das misturas (ácidas ou básicas), os estudantes obtinham o valor matemático do $\mathrm{pH}$ da mistura. Por fim, utilizando a definição do $\mathrm{pH}$ como logaritmo na base 10 para a concentração de íons $\mathrm{H}^{+}$, os estudantes obtinham a concentração de íons $\mathrm{H}^{+}$em cada solução. 
Para a realização da atividade, além da construção dos grupos, que foram organizados por sociabilidade entre os estudantes, os mesmos deveriam criar um grupo de discussão no Whatsapp, no qual o professor regente deveria estar presente, a fim de trocar informações sobre a construção do procedimento, dificuldades e avanços. O procedimento deveria ser filmado e o vídeo entregue, também, pelo grupo de mensagens. Na turma que realizou a atividade foram construídos quatro grupos de alunos. A opção pela atividade filmada, realizada fora das aulas presenciais, objetivou aferir a colaboração dos estudantes em sua realização fora do espaço físico da escola. Nesse sentido alguns grupos se reuniram na casa de algum componente do grupo para realizá-la, enquanto outros grupos prepararam todo o material e executaram a atividade na escola, porém em horário alternativo às aulas. A construção do vídeo previa o desenvolvimento de habilidades relacionadas ao uso de ferramentas tecnológicas, como elaboração de um roteiro, desenvolvimento do vídeo e edição. Nesse sentido os resultados foram surpreendentemente positivos.

Uma vez que o professor regente da disciplina participava ativamente da construção do trabalho no ambiente físico da sala de aula, além de fornecer todo o ferramental matemático sobre os temas exponencial e logaritmo, considera-se, as observações feitas pelo docente a partir dos comportamentos, questionamentos e atitudes dos estudantes offline como pesquisa-ação.

Segundo Michel Thiollent, define-se pesquisa-ação como "um tipo de pesquisa social com base empírica que é concebida e realizada em estreita associação com uma ação ou com uma resolução de um problema coletivo e no qual os pesquisadores estão envolvidos de modo cooperativo ou participativo" (THIOLLENT, 2011, p.20). De fato, ao propor o problema na atividade em questão, colocando-se como mediador e animador do processo de construção do conhecimento, por parte dos alunos, o docente age de forma cooperativa e, também, participativa, denotando a investigação como pesquisa-ação.

Ainda de acordo com Thiollent (2011), nesta metodologia os pesquisadores possuem um papel ativo tanto no equacionamento dos problemas encontrados, quanto no acompanhamento destes, assim como na avaliação das ações desencadeadas em função dos problemas.

A pesquisa-ação pode ser conduzida em várias áreas das Ciências Sociais. Sua relevância para a área de Educação ocorre pelo fato dos 
pesquisadores, nesta perspectiva, estarem em condições de produzir informações e conhecimentos de uso mais efetivo, ou seja, o contato com o "chão de fábrica" da escola pode contribuir substancialmente com as pesquisas da área e evitar o anacronismo entre saber acadêmico e prática pedagógica.

Portanto, a presença do professor nos grupos de discussão do Whatsapp deveria interferir minimamente na dinâmica dos diálogos. O professor se restringiu a fazer contato com os estudantes quando solicitado. Desta forma, o comportamento do professor online foi distinto do comportamento offline, caracterizando outra forma de coleta de dados. Para esta etapa, foram utilizadas a observação participante e a análise documental. De acordo com Lüdke e André (1986) o "observador como participante" define-se como um papel em que a identidade do pesquisador e os objetos de estudo são revelados ao grupo pesquisado desde o início. As vantagens desta posição é o acesso a informações do grupo de forma irrestrita. No entanto, este mesmo grupo pode exercer, junto ao pesquisador, algum tipo de controle sobre o que pode ou não ser divulgado.

Além da observação participante, como as mensagens trocadas estavam disponíveis no aplicativo utilizado para a coleta de dados, a construção dos grafos que representam as redes sociais existentes na turma, a partir da escuta e leitura dos diálogos trocados, pode ser classificada como análise documental. O objetivo desta metodologia foi ratificar e validar informações obtidas por outras técnicas de coleta, como é o caso da observação (LÜDKE e ANDRÉ, 1986). Cabe ressaltar que o interesse do pesquisador pela linguagem dos sujeitos, bem como suas diferentes formas de expressão dentro do grupo também reforça o uso da análise documental para uma melhor descrição do ciberespaço. A pesquisa foi realizada como parte de um projeto de pesquisa avaliado pelo Comitê de Ética em Pesquisa (CEP) da instituição no qual esta foi realizada, sendo os estudantes informados desta através de Termo de Consentimento Livre e Esclarecido (TCLE) encaminhado aos responsáveis, aceitando o convite a participar do experimento.

\section{Resultados e discussões}

Considerando-se os textos e mídias vinculadas pelos quatro grupos durante a realização da atividade, procedeu-se a análise do material sob 
dois pontos de vista: quantitativamente, com o auxílio do aplicativo NodeXL ${ }^{2}$, utilizando a Análise de Redes Sociais (ARS) e qualitativamente, a partir da classificação do trabalho interativo descrita por González e Váttimo (2012) e avaliando-se o produto final entregue por cada grupo.

Cada estudante foi representado, junto com o professor, por um nó no grafo que define a rede gerada pela troca de mensagens no grupo de Whatsapp. O tamanho do nó se refere ao volume de atividade do ator no grupo, isto é, quanto mais vezes o ator falava no grupo, maior será o tamanho do nó que o representa. As arestas indicam que houve troca de mensagens entre os atores que as ligam. A espessura da aresta também indica o volume de troca de mensagens entre os atores que estão ligados por ela: quanto mais espessa for a aresta, maior quantidade de mensagens os atores trocaram entre si.

Em função dos procedimentos metodológicos da pesquisa, o professor não deveria interferir nas conversas dos estudantes no ciberespaço, a menos para dúvidas pontuais. Essa postura foi explicada aos atores a fim de não se fragilizar a proposta de observação participante para a pesquisa. No entanto, discussões sobre o trabalho que ocorreram durante as aulas presenciais, como procedimentos para o cálculo do $\mathrm{pH}$, formas de medição do $\mathrm{pH}$ experimentalmente, utilização ou não do laboratório de química, elaboração do roteiro para a filmagem dentre outros temas, contaram com a mediação do professor, contribuindo efetivamente em algumas situações postas. Nesse sentido, do ponto de vista presencial, o procedimento metodológico foi pesquisa-ação nos encontros presenciais.

Os encontros presenciais foram promovidos em intervalos curtos, nas aulas presenciais, nos quais os estudantes deveriam discutir as ações para a realização da atividade e dúvidas poderiam ser tiradas com o professor, presencialmente. Foram nesses encontros que o desenvolvimento do cálculo de logaritmo aplicado à questão do $\mathrm{pH}$ foi realizado, de modo que os estudantes pudessem traduzir os resultados experimentais em números. Foi a partir desta observação presencial que as interações entre os estudantes foram classificadas de acordo com os critérios de Gonzáles e Váttimo (2012).

2. Este aplicativo trabalha em uma planilha de Excel, de acesso gratuito, no qual é possível construir grafos, sejam estes relacionados a redes sociais ou para outros fins. Após a construção, manualmente, dos grafos o aplicativo executa análise destes considerando métricas associadas a nós e grafos. Para acesso ao aplicativo: https://www.smrfoundation.org/nodexl/. 
A Figura 1 representa o grafo com as discussões realizadas pelo Grupo 1 pelo Whatsapp.

A Tabela 1 apresenta as médias e medianas para as métricas dos nós para o grafo representado pela Figura 1.

O nó que representa o Aluno 2 possui o maior tamanho, ou seja, foi $\mathrm{o}$ ator que mais dialogou com os demais membros do grupo, assim como possui o maior grau, o que demonstra que este indivíduo se relacionou com todos os demais. Os nós que representam os Alunos 1 e 3 também se relacionaram com todos os membros do grupo. Aluno 4 e Professor não dialogaram entre si, donde os graus dos nós que os representam são três em ambos os casos. O valor médio baixo para o grau de intermediação ou Betweenness designa que poucos nós atuaram como pontes na rede. Destaca-se que o Aluno 4 e o Professor obtiveram valor nulo para este parâmetro, o que indica uma tentativa dos Alunos 1, 2 e 3 de se relacionarem com esses dois atores, aparentemente fora da maior parte das discussões. Cabe lembrar que o Professor, como observador participante, está de fato fora das discussões.

Figura 1. Grafo que representa a troca de mensagens do Grupo 1.

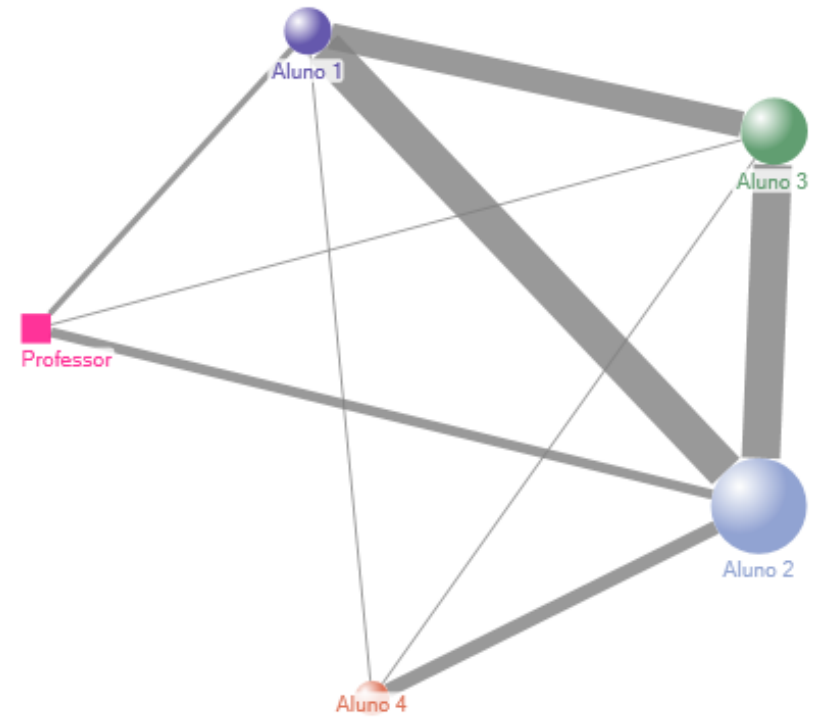

Fonte: A autora, 2020. 
Tabela 1. Métricas de nó para o grafo da Figura 1.

\begin{tabular}{|l|l|l|}
\hline \multicolumn{1}{|c|}{ Métrica de nó } & Média & Mediana \\
\hline Grau do nó & 3,6 & 4 \\
\hline Grau de intermediação & 0,200 & 0,333 \\
\hline Grau de proximidade & 0,23 & 0,25 \\
\hline Centralidade autovetor & 0,200 & 0,215 \\
\hline PageRank Fonte: A autora, 2020. & 1 & 1,099 \\
\hline
\end{tabular}

A Tabela 2 apresenta as métricas de rede referentes ao grafo representado pela Figura 1.

Tabela 2. Métricas de rede para o grafo da Figura 1.

\begin{tabular}{|l|c|}
\hline \multicolumn{1}{|c|}{ Métrica de rede } & Valor médio \\
\hline Densidade & 0,9 \\
\hline Coeficiente de clusterização & 0,9 \\
\hline \multicolumn{2}{|c|}{ Fonte: A autora, 2020. } \\
\hline
\end{tabular}

O grau de proximidade entre os nós não foi tão discrepante: valor máximo para os nós que representam os Alunos 1, 2 e 3 com 0,25 e o valor de 0,20 para o Aluno 4 e o Professor. Isso significa que todos os nós estão relativamente próximos uns dos outros na rede. A centralidade autovetor também não foi muito distinta para os nós da rede: 0,215 para os nós que representam os Alunos 1, 2 e 3 e 0,177 para os nós que representam o Aluno 4 e o Professor. O mesmo ocorre para o PageRank. Os nós que representam os Alunos 1, 2 e 3 obtiveram o valor de 1,099 enquanto que os nós que representam o Aluno 4 e o Professor tiveram os valores de 0,851 . A centralidade do tipo autovetor avalia as conexões diretas e indiretas de um determinado nó. Podemos concluir, portanto, que os nós representantes dos Alunos 1, 2 e 3 possuem maior conexão (direta e indireta) do que os nós que representam o Aluno 4 e o Professor, em coerência à Figura 1.

A partir da Tabela 2 é possível observar que o grafo é denso, uma vez que a densidade se refere à quantidade de conexões efetivas em relação ao total de conexões possíveis. Portanto o grafo da Figura 1 realiza $90 \%$ das conexões totais possíveis. O coeficiente de clusterização 0,9 
indica, de acordo com Barabási (2003), que os componentes da rede possuem um bom relacionamento entre $\mathrm{si}^{3}$

A Figura 2 apresenta o grafo que representa a rede formada pelos diálogos entre os estudantes pertencentes ao Grupo 2.

A primeira diferença entre os Grupos 1 e 2 é o número de componentes: enquanto o Grupo 1 tinha quatro componentes (cinco considerando o estudante sem aparelho celular e que não está no ciberespaço), o Grupo 2 possui cinco componentes.

Figura 2. Grafo que representa a troca de mensagens do Grupo 2.

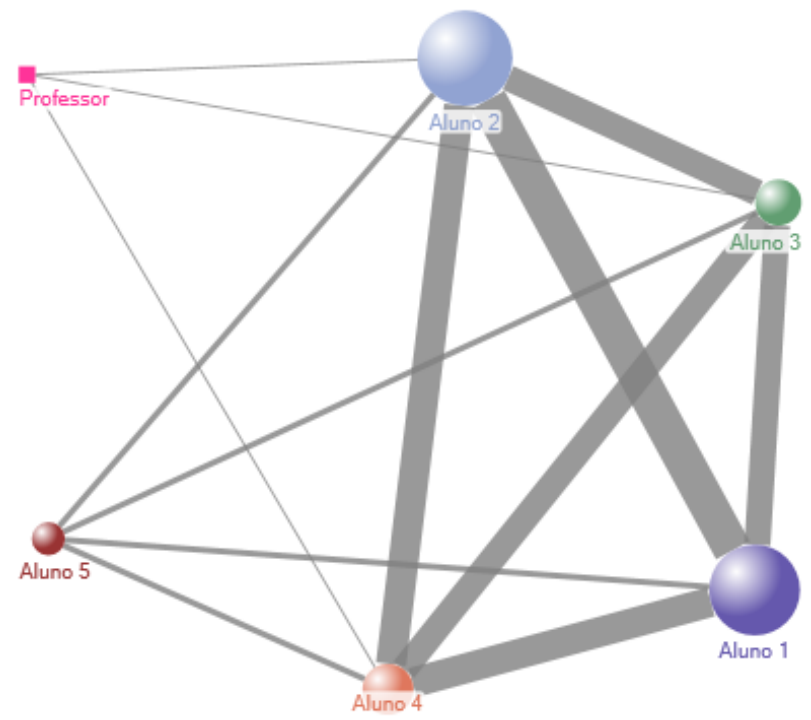

Fonte: A autora, 2020.

Destaca-se que o tamanho dos nós representantes dos Alunos 1 e 2 são muito próximos, o que demonstra quase que a mesma representatividade destes dois autores no que concerne ao volume de mensagens enviadas por ambos. Observa-se, também, que a aresta de maior espessura é a que liga os nós que representam os Alunos 1 e 2, donde podese concluir que foram os atores que mais trocaram mensagens entre si.

3. Os valores para as métricas indicados nas tabelas ao longo do texto foram gerados por uma rotina do NodeXL. A montagem dos grafos foi feita manualmente baseada nas métricas de pesos determinadas pelo próprio aplicativo, em comparação com o volume de atividade dos atores, proporcionalmente. 
O Professor, como observador participante, trocou poucas mensagens com somente três componentes do grupo.

A Tabela 3 apresenta as médias e medianas para as métricas dos nós do grafo representado na Figura 2.

Tabela 3. Métricas de nó para o grafo da Figura 2.

\begin{tabular}{|l|c|c|}
\hline \multicolumn{1}{|c|}{ Métrica de nó } & Média & Mediana \\
\hline Grau do nó & 4,333 & 4,5 \\
\hline Grau de intermediação & 0,333 & 0,333 \\
\hline Grau de proximidade & 0,179 & 0,183 \\
\hline Centralidade autovetor & 0,167 & 0,173 \\
\hline PageRank & 1 & 1,033 \\
\hline
\end{tabular}

A Tabela 4 apresenta as métricas de rede referentes ao grafo representado na Figura 2.

Tabela 4. Métricas de rede para o grafo da Figura 2.

\begin{tabular}{|l|c|}
\hline \multicolumn{1}{|c|}{ Métrica de rede } & Valor médio \\
\hline Densidade & 0,867 \\
\hline Coeficiente de clusterização & 0,9 \\
\hline \multicolumn{2}{|c|}{ Fonte: A autora, 2020.} \\
\hline
\end{tabular}

De forma semelhante ao grafo da Figura 1, o valor médio baixo para o grau de intermediação indica que poucos nós funcionam como pontes entre dois grupos: os Alunos 1 e 5, assim como o Professor não colaboram nesse sentido. Os demais nós tem o mesmo grau de intermediação, ou seja, exercem o papel de ponte da mesma forma. O grau de proximidade indica que os Alunos 2, 3 e 4 (iguais a 0,200 e maior valor na rede) estão mais próximos entre si, seguidos dos Alunos 1 e 5, com valor igual a 0,167 . O Professor teve grau de proximidade 0,143 . A centralidade autovetor apresentou um comportamento semelhante ao grau de proximidade: Alunos 2, 3 e 4 com 0,184; Alunos 1 e 5 com 0,161 e Professor 0,125. De fato, o subgrupo formado pelos Alunos 2, 3 e 4 possui um maior número de conexões direta e indireta no grafo. Por fim, o PageRank ratifica o resultado da centralidade autovetor: 1,138 para os Alunos 2,3 e 4, 0,927 para os Alunos 1 e 5 e 0,73 para o Professor. A partir 
destes dados, observa-se a formação de um subgrupo formado pelo Alunos 2, 3 e 4, o qual se relacionou mais entre si e com os demais componentes da rede. Os Alunos 1 e 5 contribuíam em menor volume para as discussões e o Professor, dessa vez, teve um papel maior como observador do processo.

Em relação às métricas de rede, a densidade do grafo representado na Figura 2 foi ligeiramente menor do que a densidade do grafo representado na Figura 1, utilizando 86,7\% das conexões possíveis. O coeficiente de clusterização foi idêntico, o que demonstra, novamente, um bom relacionamento entre os atores da rede.

A Figura 3 apresenta o grafo representativo dos diálogos realizados pelo Grupo 3.

O Grupo 3, formado por quatro integrantes como o Grupo 1, tem no Aluno 3 o ator com maior volume de mensagens enviadas ao grupo, indicado, na Figura 3, pelo tamanho do nó que o representa. É possível observar, também, que o maior volume de mensagens foi trocado entre os Alunos 3 e 4. O Professor, novamente, não trocou mensagens com todos os elementos do grupo.

Figura 3. Grafo que representa as trocas de mensagens entre o Grupo 3.

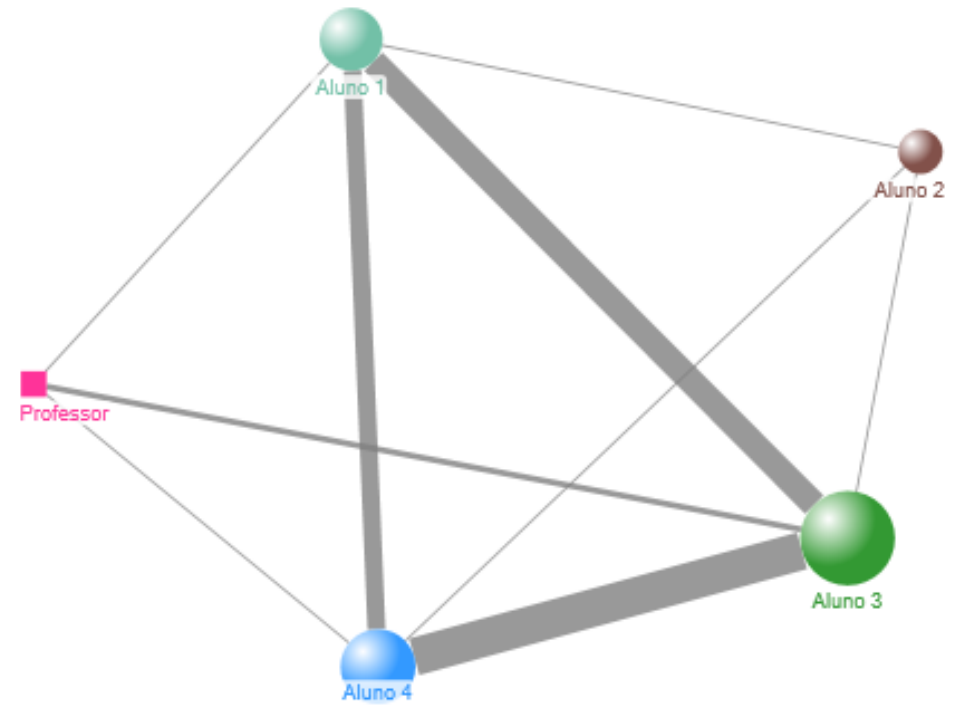

Fonte: A autora, 2020. 
A Tabela 5 apresenta os valores para as métricas dos nós referentes ao grafo representado na Figura 3.

Tabela 5. Métricas de nó para o grafo da Figura 3.

\begin{tabular}{|l|c|l|}
\hline \multicolumn{1}{|c|}{ Métrica de nó } & Média & Mediana \\
\hline Grau do nó & 3,6 & 4 \\
\hline Grau de intermediação & 0,2 & 0,333 \\
\hline Grau de proximidade & 0,23 & 0,25 \\
\hline Centralidade autovetor & 0,200 & 0,215 \\
\hline PageRank Fonte: A autora, 2020. & 1 & 1,099 \\
\hline \multicolumn{2}{|c|}{} \\
\hline
\end{tabular}

A Tabela 6 apresenta as métricas de rede referentes ao grafo representado na Figura 3.

Tabela 6. Métricas de rede para o grafo da Figura 3.

\begin{tabular}{|l|c|}
\hline \multicolumn{1}{|c|}{ Métrica de rede } & Valor médio \\
\hline Densidade & 0,9 \\
\hline Coeficiente de clusterização & 0,9 \\
\hline
\end{tabular}

Fonte: A autora, 2020.

Os valores obtidos para as métricas de nó e para as métricas de rede para os grafos das Figuras 1 e 3 são idênticos, o que demonstra um comportamento semelhante entre os dois grupos: três estudantes se relacionam com maior intensidade, formando um subgrupo. No entanto a centralidade autovalor e o PageRank demonstram pouca diferença entre as quantidades de conexões diretas e indiretas dos nós. A densidade de 0,9 novamente representa que $90 \%$ das conexões totais foram efetivamente realizadas e o coeficiente de clusterização de 0,9 indica, também, um bom relacionamento entre os atores da rede.

Por fim a Figura 4 apresenta o grafo que representa os diálogos estabelecidos pelo Grupo 4. 
O grafo representado na Figura 4 é substancialmente diferente dos grafos representados pelas Figuras 1, 2 e 3. Observa-se que os atores da rede possuem o mesmo volume de diálogos, uma vez que os vértices possuem o mesmo tamanho. Não há troca de mensagens entre os membros. Cada um estabelece comunicação apenas com o professor, e com a mesma intensidade, representada pela mesma espessura das arestas.

A Tabela 7 apresenta os valores para as métricas dos nós associadas ao grafo representado na Figura 4.

Em virtude da baixa comunicação estabelecida entre os atores na rede, a média de grau, por nó, foi a mais baixa de todos os grupos: 1,5. Apenas o nó representativo do Professor apresentou grau de intermediação, cujo valor foi 3 (mediana foi nula pois os demais nós não apresentaram esse parâmetro), uma vez que só o Professor foi ponte entre os demais nós. O grau de proximidade foi igual a 0,333 para o Professor e 0,200 para os demais atores da rede.

Figura 4. Grafo que representa as trocas de mensagem entre o Grupo 4.

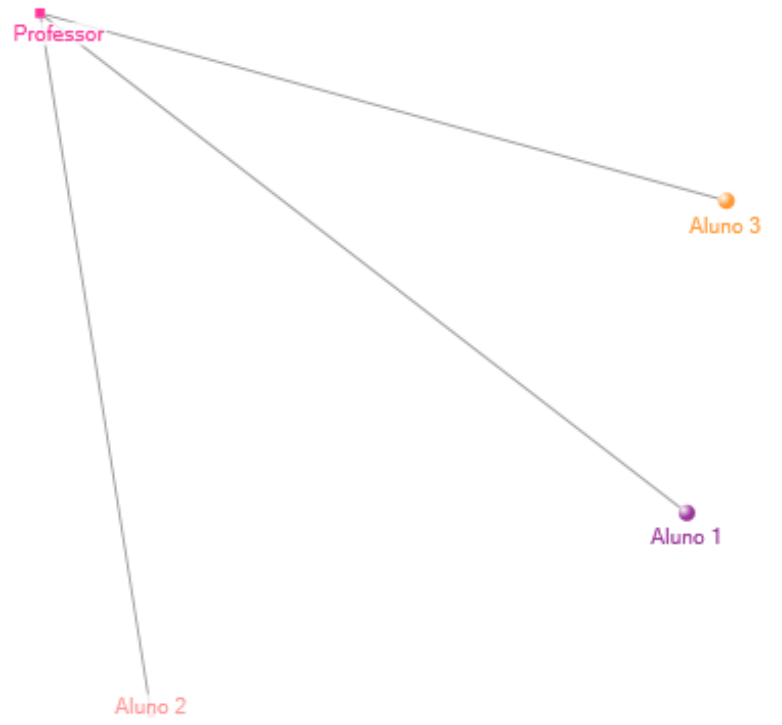

Fonte: A autora, 2020. 
Tabela 7. Métricas de nó para o grafo da Figura 4.

\begin{tabular}{|l|c|c|}
\hline Métrica de nó & Média & Mediana \\
\hline Grau do nó & 1,5 & 1 \\
\hline Grau de intermediação & 0,75 & 0,000 \\
\hline Grau de proximidade & 0,233 & 0,20 \\
\hline Centralidade autovetor & 0,25 & 0,25 \\
\hline PageRank & 1 & 0,694 \\
\hline \multicolumn{2}{|l|}{ Fonte: A autora, 2020. } \\
\hline
\end{tabular}

Tabela 8. Métricas de rede para o grafo da Figura 3.

\begin{tabular}{|l|c|}
\hline Métrica de rede & Valor médio \\
\hline Densidade & 0,5 \\
\hline Coeficiente de clusterização & 0,000 \\
\hline
\end{tabular}

Fonte: A autora, 2020.

A centralidade autovalor foi igual para todos o nós, ou seja, 0,25. Avaliando conexões diretas e indiretas, os nós tiveram comportamento semelhante. O PageRank apresentou o valor 1,919 para o Professor e o valor 0,694 para os nós que representam os Alunos 1, 2 e 3, evidenciando um maior número de conexões do Professor em relação aos demais atores da rede.

A densidade de 0,5 indica que apenas $50 \%$ das conexões que poderiam ser estabelecidas na rede foram, de fato, utilizadas. O coeficiente de clusterização nulo indica, segundo Barabási (2003), ausência de relação entre os membros da rede: o Professor é o único elo que une os Alunos 1,2 e 3.

Iniciando a análise qualitativa dos dados, realizada pela observação e diálogo com os estudantes em sala de aula, verificou-se, a partir das trocas de mensagens de cada grupo, que o Grupo 2 era o mais coeso: quatro dos cinco integrantes dialogaram bastante. O Aluno 2 era o hub, ou seja, quase todos os diálogos passavam por este ator. O vídeo entregue pelo grupo descrevendo o procedimento mostra apenas o Aluno 2 conforme a Figura 5, o que demonstra a confiança dos demais membros do grupo neste ator. Este vídeo, também, foi o melhor produzido, atingindo $80 \%$ dos objetivos da atividade proposta: os estudantes fizeram a 
solução a partir do repolho roxo, misturaram às substâncias sugeridas, mediram o pH de cada solução e classificaram as mesmas em ácidas e básicas. No entanto não calcularam o valor das concentrações de íons $\mathrm{H}^{+}$.

Do ponto de vista do trabalho interativo classificado por González e Váttimo (2012), o Grupo 2 foi o que melhor trabalhou coletivamente, demonstrando interação entre os membros e mentalidade colaborativa. Tais aspectos foram analisados considerando, também, o comportamento offline dos membros, que se mostraram interessados e em sintonia durante o planejamento e execução da atividade.

Figura 5. Procedimento realizado pelo Grupo 2.

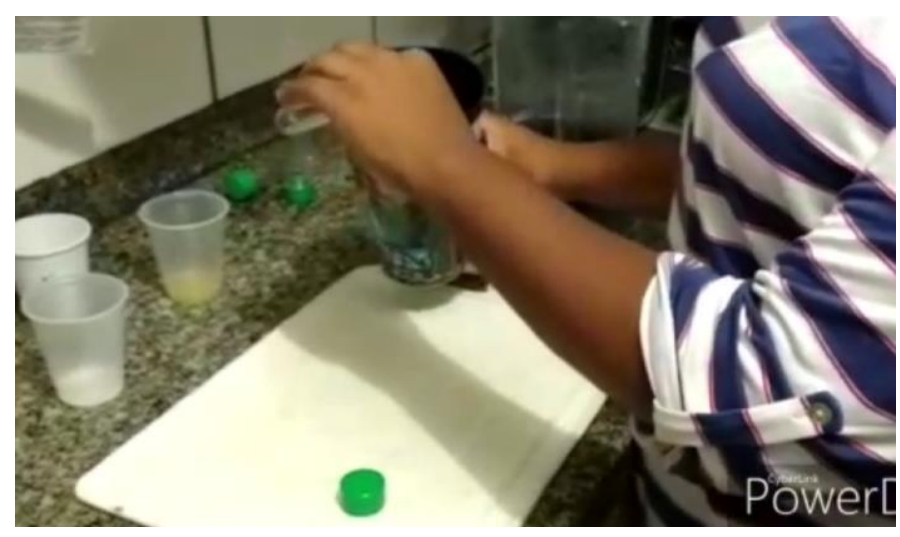

Fonte: A autora, 2020.

Os Grupos 1 e 3 obtiveram os mesmos valores para as métricas dos nós e métricas de rede. No entanto, do ponto de vista qualitativo, os grupos atuaram de forma bem diferente. O Grupo 1, em seu vídeo dedicou, aproximadamente, $20 \%$ do tempo com o procedimento e $80 \%$ com os cálculos das concentrações dos íons $\mathrm{H}^{+}$. A Figura 6 apresenta o cálculo desta concentração para o limão, a partir dos dados obtidos, pelos estudantes, no procedimento. Este grupo atingiu todos os objetivos da atividade proposta. Destaca-se que um estudante do grupo não tinha celular e, portanto, não interagiu com o grupo online, apenas offline. Todos os estudantes participaram do vídeo: cada estudante explicou o cálculo da concentração de íons $\mathrm{H}^{+}$para uma solução. De acordo com González e Váttimo (2012), houve interação no grupo e atuaram com a mentalidade colaborativa. 
Figura 6. Cálculo da concentração de íons $\mathrm{H}^{+}$pelo Grupo 1.

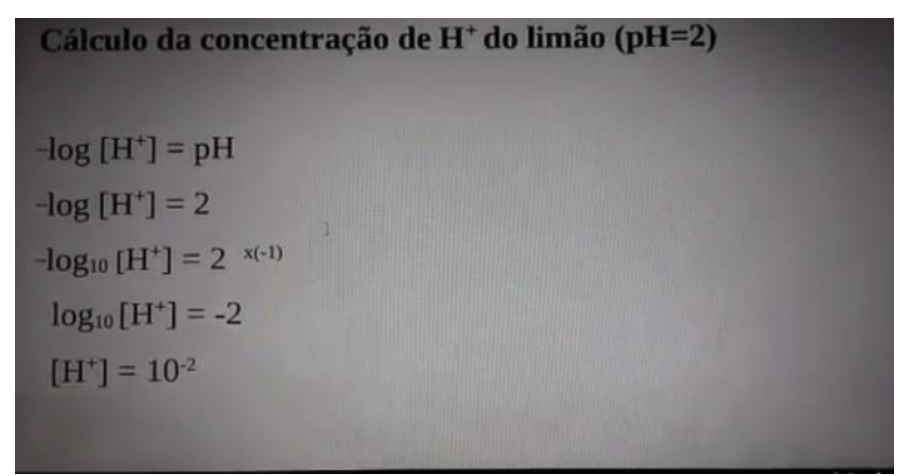

Fonte: A autora, 2020.

O Grupo 3 realizou a atividade em duas etapas: os Alunos 1, 3 e 4 se reuniram, realizaram o experimento e filmaram. Os cálculos das concentrações dos íons $\mathrm{H}^{+}$foram realizados pelo Aluno 2, que pouco interagiu com os demais, conforme a Figura 3 demonstrou. $\mathrm{O}$ grupo atingiu todos os objetivos da atividade proposta, sendo que a interação entre os componentes, do ponto de vista de Gonzáles e Váttimo (2012), foi intermediária, ou seja, houve interação entre os membros, mas não houve mentalidade colaborativa, uma vez que o Aluno 2 atuou isoladamente em suas atividades no grupo.

Finalizando a análise, o Grupo 4 foi o que pouco discutiu a atividade de forma online. $\mathrm{O}$ vídeo apresentado demonstrou o procedimento parcialmente, não revelando como se obtém a solução do repolho roxo para se misturar nas outras substâncias. Foram entregues dois vídeos ao invés de um: o primeiro com o procedimento e o segundo com os cálculos. O segundo vídeo mostra, de forma didática, como se obtém a concentração de íons $\mathrm{H}^{+}$, conforme mostra a Figura 7. Tal fato não era necessário, pois as contas poderiam ser feitas na calculadora e apresentadas, corroborando com a visão de Boaler (2018) sobre o uso de tecnologia para cálculos. Apenas um ator atuou em ambos os vídeos. Em sala de aula, o Grupo 4 também não interagiu, sendo o Aluno 3 o responsável por todo o trabalho. Portanto, não houve interação entre a equipe do ponto de vista de González e Váttimo (2012). 
Figura 7. Demonstração do cálculo da concentração de íons $\mathrm{H}^{+}$pelo Grupo 4 .

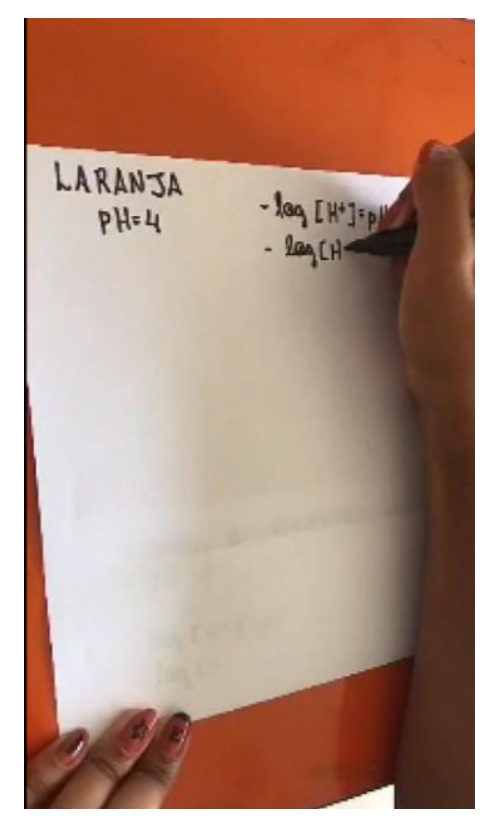

Fonte: A autora, 2020.

\section{Considerações Finais}

Este trabalho estudou a importância das relações estabelecidas no ciberespaço e os desdobramentos destes novos territórios de troca de informações e conhecimentos no âmbito da escola clássica. Nos diálogos estabelecidos pelos atores durante a realização da atividade proposta, percebeu-se a interação dos estudantes em assuntos inerentes ao trabalho, troca de informações através de links e vídeos pertinentes ao tema, além de momentos de descontração, nos quais memes eram vinculados e brincadeiras entre os atores da rede estabelecidas. Foi a partir da análise documental proposta por Lüdke e André (1986) que foi possível entender a linguagem utilizada pelos sujeitos e analisar a sua relevância no contexto. Não foram registradas discussões acaloradas nem ofensas aos atores. Observou-se, também, um esforço identitário de cada grupo, os quais fizeram questão de colocar uma foto de perfil que identificasse o grupo, além dos nomes sugestivos utilizados para estes como "Hora do show!" ou "Quarteto e a professora". O único aluno sem aparelho celular e, portanto, sem acesso à rede estabelecida no ciberespaço, teve sua 
atuação limitada na atividade, ou seja, o actante (aparelho celular) na perspectiva de Latour (2012) foi fundamental nas relações sociais online estabelecidas pelo grupo. Registrou-se que ele realizou algo discutido pelo grupo sem a sua presença, pois as tarefas de todos foram discutidas no ciberespaço.

Apesar da atividade proposta ser pouco complexa do ponto de vista matemático, esta atendeu aos objetivos de formação para o curso técnico em química. Questões relacionadas aos procedimentos de laboratório, aliadas aos erros de experimentação, uma vez que os resultados encontrados para os valores de $\mathrm{pH}$ foram aproximados, oportunizaram discussões valiosas para os estudantes ainda no primeiro ano do ensino médio. A atividade contemplou, de acordo com Wagner (2008), as seguintes quatro habilidades: pensamento crítico e solução de problemas; colaboração em rede e aprendizagem por influência; acesso a informações para análise; curiosidade e imaginação, dentre as sete habilidades de sobrevivência estabelecidas pelo autor.

Do ponto de vista do processo de interação das equipes estabelecido por Gonzáles e Váttimo (2012), 50\% dos grupos interagiram e desenvolveram mentalidade colaborativa. Tal sincronia foi favorecida pela inserção dos aparelhos celulares no cotidiano dos estudantes e pela ampliação do ambiente da sala de aula para além de suas paredes.

Portanto a pergunta de pesquisa foi respondida a partir dos resultados obtidos: de fato a colaboração realizada no ciberespaço contribui para a mentalidade colaborativa do grupo, ao mesmo tempo que proporciona o desenvolvimento de habilidades que a sala de aula física não é mais capaz de suprir. Ao lidarem com uma situação prática e, a partir dela, retirarem suas conclusões, cada grupo pode, individual ou coletivamente, construir seu conhecimento (LÉVY, 1999).

Conclui-se que o ciberespaço amplifica as trocas de conhecimento, favorece a aprendizagem de forma colaborativa, da mesma forma que modifica a escola clássica. Os relacionamentos em rede proporcionam novos ambientes de aprendizagem e de disseminação da informação, alterando o papel do docente no processo de construção do conhecimento por parte do alunado. A partir da Análise de Redes Sociais (ARS) estabelecida neste artigo, observa-se que a interação nas redes, demonstrada pelos indicadores métricos da ARS e a efetividade colaborativa na atividade em grupo, segundo Gonzáles e Váttimo (2012) se relacionam: 
quanto maior a atividade no ciberespaço, indicadas pelos parâmetros da ARS, mais bem-sucedidos colaborativamente estão os grupos, de acordo com os parâmetros de Gonzáles e Váttimo (2012). É a internet modificando substancialmente as relações sociais e apresentando um novo olhar para a escola e para a função docente.

Recebido em: 14/01/2020

Aprovado em: 09/07/2020

\section{Referências}

BARABÁSI, A. L. Linked. How Everything is Connected to Everything else and what it means for Business, Science and Everyday Life. Cambridge: Plume, 2003.

BASTOS, M. T.; RECUERO, R.; ZAGO, G. Encontros e desencontros entre TAR e ARS: o laço fraco entre teoria e método. Contemporânea: comunicação e cultura, v.12, n.3, set./dez. 2014.

BRASIL. Ministério da Educação. Base Nacional Comum Curricular. Brasília-DF, 2018.

BOALER, J. Mentalidades Matemáticas. Porto Alegre: Penso, 2018.

GÓMEZ, A. I. P. Competências ou pensamento prático? A construção dos significados de representação e de ação. In: SACRISTÁN, J. G; GÓMEZ, A. I. P.; RODRIGUEZ, J. B. M.; SANTOMÉ, J. T.; RASCO, F. A.; MÉNDEZ, J. M. A. Educar por competências: o que há de novo? Porto Alegre: Artmed, 2011, p. 64-114.

GONZÁLEZ, F.; VÁTTIMO, S. Processos de Inteligencia Colectiva y Colaborativa en el Marco de Tecnologías WEB 2.0: Conceptos, Problemas y Aplicaciones. In: Anuario de Investigaciones, v. XIX, Universidad de Buenos Aires, Argentina, 2012.

LATOUR, B. Reagregando o social. Salvador: Edufba, 2012.

LÜDKE, M.; ANDRÉ, M. Pesquisa em educação: abordagens qualitativas. São Paulo: EPU, 1986.

LÉVY, P. Cibercultura. São Paulo: Editora 34, 1999.

RECUERO, R. Redes sociais na internet. $2^{a}$ edição. Porto Alegre: Sulina, 2018.

RECUERO, R.; BASTOS, M.; ZAGO, G. Análise de Redes para Mídia Social. Porto Alegre: Sulina, 2018. 
TARDIF, M. Saberes Docentes e Formação Profissional. $17^{\text {a }}$ edição. Petrópolis, RJ: Vozes, 2014.

THIOLLENT, M. Metodologia da pesquisa-ação. $18^{\mathrm{a}}$ edição. São Paulo: Cortez, 2011.

WAGNER, T. The Global Achievement Gap: why even our best schools don't teach the new survival skills our children need - and what we can do about it. New Your: Basic Books, 2008.

ZABALA, A.; ARNAU, L. Como aprender e ensinar competências. Porto Alegre: Artmed, 2010. 